Wesllay Carlos Ribeiro ${ }^{1}$

\title{
A MEDIAÇÃO COMO MEIO DE RESOLUÇÃO DE CONFLITOS NA ÁREA DE SAÚDE
}

Mediation as a means of resolving conflicts in the healthcare area

${ }^{1}$ Universidade Federal de Alfenas - Campus Varginha. Varginha/MG, Brasil. Correspondência: Wesllay Carlos Ribeiro. E-mail: wesllay.ribeiro@gmail.com.

Recebido: 14/10/2016. Revisado: 17/04/2017. Aprovado: 30/06/2017. 


\section{RESUMO}

O estudo aborda a utilização institucional da mediação na área de saúde. A mediação tem sido utilizada em vários países e se apresentado como uma tendência mundial em diferentes temas, entre eles o acesso à saúde. No Brasil, se têm notícias de algumas iniciativas com a finalidade de utilizar a mediação como meio de resolução de controvérsias na área de saúde, todavia é necessário cuidado e debate sobre essas técnicas a fim de que não se tornem meios de aumento da desigualdade social.

\section{Palavras-Chave}

Acesso aos Serviços de Saúde; Assistência à Saúde; Negociação; Política de Saúde.

\section{ABSTRACT}

The study addresses the institutional use of mediation in the area of healthcare. Mediation has been used in a number of countries indicating a worldwide trend in different topics, including healthcare access. In Brazil there have been reports of some initiatives aimed at using mediation as a means of resolving controversies in the area of healthcare, however caution and debate are necessary on these techniques so they do not become a means of increasing social inequality.

\section{Keywords}

Delivery of Health Care; Health Policy; Healthcare Services Accessibility; Negotiation. 


\section{Introdução}

Não são recentes as discussões, os estudos e as pesquisas acerca da necessidade de garantia e efetividade do acesso aos direitos, assim como também não é recente a necessidade de que as demandas individuais e coletivas obtenham resultado em um prazo razoável.

Entre esses estudos, um que chama a atenção é a Pesquisa Nacional por Amostra de Domicílios (PNAD), no suplemento "Características da vitimização e do acesso à justiça no Brasil", publicado em 2009, cujo objetivo foi "conhecer se foi utilizado ou não o Poder Judiciário, ou quais os motivos que tenham desestimulado as pessoas na busca da justiça"'. Nessa pesquisa, observou-se que $57,8 \%$ da população recorria à justiça e 12,4\% ao Juizado Especial para resolver seus conflitos. Todavia, dos que não buscaram a solução de seus conflitos na justiça, cerca de $30 \%$ (ou 3,8 milhões de pessoas) apontaram como motivos para não fazê-lo o "fato de a solução do problema ter ocorrido por meio de mediação ou conciliação, 27,6\%, e a percepção de que demoraria muito, 15,9\%".

Esforços têm sido empreendidos por juristas e profissionais de diferentes áreas almejando alcançar meios e formas que possibilitem um melhor equacionamento entre a previsão e garantia de direitos na legislação e o acesso efetivo ao exercício de tais direitos no cotidiano das pessoas e instituições.

O Instituto de Pesquisa Econômica Aplicada (Ipea), em pesquisa realizada no território nacional, publicou em 2011 o Sistema de Indicadores de Percepção Social, Justiça. Os dados obtidos pelo Ipea e apresentados na Tabela 1 ilustram a percepção negativa que os cidadãos têm da justiça no Brasil.

Tabela 1. Percepção que os cidadãos têm da justiça no Brasil.

\begin{tabular}{|c|c|c|c|c|c|c|}
\hline & Rapidez & Acesso & Custo & $\begin{array}{l}\text { Decisões } \\
\text { justas }\end{array}$ & Honestidade & Imparcialidade \\
\hline $\begin{array}{l}\text { Média } \\
\text { nacional }\end{array}$ & 1,19 & 1,48 & 1,45 & 1,60 & 1,18 & 1,18 \\
\hline
\end{tabular}

${ }^{1}$ IBGE - INSTITUTO BRASILEIRO DE GEOGRAFIA E ESTATÍSTICA. Pesquisa Nacional por Amostra de Domicílios - PNAD. Características da vitimização e do acesso à justiça no Brasil. 2009. Disponível em <http:// biblioteca.ibge.gov.br/visualizacao/livros/liv47311.pdf> Acesso em: 05 abr. 2017.

${ }^{2}$ IPEA - INSTITUTO DE PESQUISA ECONÔMICA APLICADA. Sistema de Indicadores de percepção Social. Justiça, 31 maio 2011. p. 7. Disponível em <http://www.ipea.gov.br/portal/images/stories/PDFs/SIPS/110531_ sips_justica.pdf> Acesso em: 05 abr. 2017. 
Desses dados, depreende-se que, na percepção do cidadão brasileiro, a justiça no Brasil é considerada abaixo de regular - não se podendo destacar nenhum dos quesitos separadamente, vez que no geral a avaliação sobre cada um manteve-se muito próxima e abaixo da avaliação regular.

Por outro lado, esses dados confrontam com uma situação contraditória no país, pois, se de um lado a percepção social demonstra a pouca confiança no justiça do país para resolver os conflitos, por outro se tem verificado uma crescente judicialização de direitos e políticas públicas ${ }^{3}$.

No caso do direito à saúde, essa tendência à judicialização tem sido objeto de debate institucional, como se pode verificar por meio de recente estudo realizado pelo Conselho Nacional de Justiça $(\mathrm{CNJ})^{4}$, publicado em 2015, que objetivou analisar o "panorama da judicialização da saúde e da política judiciária de saúde no Brasil". Entre os muitos desafios e propostas que são apresentados no documento, destaca-se a necessidade de o Judiciário estabelecer meios de capacitação que possibilitem aos atores políticos, jurídicos e participativos envolvidos na resolução do conflito transitar na área de saúde. Dentre essas capacidades, está o desenvolvimento de "competências e habilidades práticas de mediação, construção do consenso e diálogo institucional focados em saúde". Chama a atenção o fato que este evolver dos conflitos na área de saúde passe a reconhecer a necessidade de extrapolar a esfera da ação judiciária, requerendo alternativas institucionalizadas que incluam também a esfera política e a dos demais entes envolvidos.

Nessa busca por soluções, muitas vezes as respostas ou ao menos a propostas de novas alternativas apontam para a utilização e a disponibilização de mecanismos institucionais diversos daqueles dos meios judiciais.

Outrossim, objetiva-se nesta pesquisa averiguar a existência no Brasil de iniciativas institucionais de aplicação da mediação como meio para resolução de conflitos na área de saúde.

Destarte, como o objetivo é a busca por iniciaiva institucionais, tentou-se fazer um uma pesquisa ampla e irrestrita a fontes governamentais, judiciais ou de outros órgãos ligados ao Judiciário. Para tanto, a pesquisa utilizou os principais motores de busca da internet com o descritor "mediação em saúde", a fim de verificar a existência de iniciativas institucionalizadas de mediação em saúde. Foram selecionadas aquelas iniciativas que envolvessem propostas de resolução extrajudicial dos conflitos na área de saúde e que fossem promovidas pela ação institucional de órgãos públicos, orgãos juridícos (não judiciais) e sociedade.

\footnotetext{
${ }^{3}$ VIANNA, Luiz Werneck; BURGOS, Marcelo Baumann; SALLES, Paula Martins. Dezessete anos de judicialização da política. Tempo soc., São Paulo, v. 19, n. 2, p. 39-85, nov. 2007. Disponível em <http://www.scielo.br/ scielo.php?script=sci_arttext\&pid=S0103-20702007000200002\&lng=pt\&nrm=iso>. Acesso em: 07 abr. 2017. http://dx.doi.org/10.1590/S0103-20702007000200002.

${ }^{4}$ ASENSI, Felipe Dutra; PINHEIRO, Roseni (Coords.). Judicialização da saúde no Brasil: dados e experiência. Brasília: Conselho Nacional de Justiça, 2015.
} 


\section{I. $\quad 0$ acesso à justiça}

A conhecida obra sobre o tema do acesso à justiça de Cappelletti e Garth ${ }^{5}$ aborda como o Direito, antes centrado em si próprio e até tendente a criar uma ciência pura, passou a ser um ramo do conhecimento sob olhares e análises de diferentes enfoques e por diferentes pesquisadores. Não só os juristas passaram a se ocupar das questões jurídicas, mas também sociólogos, economistas, cientistas políticos, antropólogos e gestores públicos. Essa miríade de diferentes conhecimentos sobre o mesmo objeto de estudo tem forçado o profissional de Direito a buscar novos horizontes e a produzir respostas que possam dar conta das questões que sobre a ciência jurídica são colocadas.

Nesse sentido é que, para Santos 6 , a expansão do Direito Constitucional ocorrida após a Segunda Guerra Mundial, com a conquista de novos direitos sociais, culturais e econômicos e a decorrente expansão do Estado-Providência, elevou a questão do acesso à justiça a uma espécie de elo que, uma vez atendido, proporcionaria a ação da justiça. Pelo oposto, ou seja, a impossibilidade de acesso à justiça, por si só acarretaria desde o início a denegação de toda e qualquer justiça. Ainda segundo aquele autor, a tramitação procesl não poderia ser reduzida a uma dimensão iminentemente técnica e socialmente neutra, devendo investigar as funções sociais e o modo como as opções técnicas acarretavam consequências sociais às partes envolvidas na disputa - circunscrevendo, portanto, a necessidade de que a ciência jurídica não se enclausure e busque as contribuições de outras áreas do saber.

O tema do acesso à justiça posto sob discussão e análise dessas diferentes lentes, no entendimento de Cappelletti e Garth ${ }^{7}$, constitui "o ponto central da moderna processualística", e "seu estudo pressupõe um alargamento e aprofundamento dos objetivos e métodos da moderna ciência jurídica”. Para os mesmos autores, o acesso à justiça, ao menos nos países de tradição ocidental, pode ser discutido em três posições básicas. A primeira dessas posições se caracteriza pela busca de assistência jurídica, visando basicamente ao acesso dos menos favorecidos ao sistema judiciário e à proteção de direitos individuais. A segunda seria caracterizada para proporcionar o acesso ao Judiciário de grupos identificados ou não com a finalidade de proporcionar proteção a direitos coletivos e difusos. Já a terceira posição buscaria um enfoque amplo, centrado na noção de acesso à justiça e, além de incluir os avanços decorrentes dos posicionamentos anteriores, se propõem a ir além e discutir formas de acesso à justiça de modo mais geral, articulado e compreensivo. Na linha dessa terceira posição, estariam a criação de órgãos especializados e a institucionalização de formas alternativas ao sistema judiciário tradicional para a solução de conflitos.

\footnotetext{
${ }^{5}$ CAPPELLETTI, Mauro; GARTH, Bryant. Acesso à justiça. Reimpr. Tradução Ellen Gracie Northfleet. Porto Alegre: Fabris, 2015.

${ }^{6}$ SANTOS, Boaventura de Sousa. Pela mão de Alice: o social e o político na Pós-Modernidade. 7. ed. Porto: Edições Afrontamento, 1999.

${ }^{7}$ CAPPELLETTI, Mauro; GARTH, Bryant. op. cit., p. 13.
} 
No Brasil, a assistência jurídica gratuita foi prevista em 1988 como um serviço oficial, prestado por um órgão público, com mecanismos para a implementação de direitos e garantias legais, para uma melhor distribuição da justiça e para o alcance da pacificação social ${ }^{8}$.

Ainda para a ampliação dos serviços de assistência jurídica, a Emenda Constitucional n. 80/2014, estabelece no artigo 98 do Ato das Disposições Constitucionais Transitórias que, no "prazo de 8 (oito) anos, a União, os Estados e o Distrito Federal deverão contar com defensores públicos em todas as unidades jurisdicionais" e ainda que "a lotação dos defensores públicos ocorrerá, prioritariamente, atendendo as regiões com maiores índices de exclusão social e adensamento populacional”"

Na esfera de proteção dos direitos coletivos e difusos, por sua vez, a instituição da ação civil pública pela Lei n. $7.347 / 1985^{10}$, vem estabelecer importante instrumento de defesa desses direitos, similar à class action nos Estados Unidos da América.

Também se encontram em nosso Judiciário tentativas de criação de órgãos especializados em determinados temas jurídicos. Quanto às formas alternativas de solução de conflitos, a Lei n. 9.307/1996 ${ }^{11}$, que trata da arbitragem, e a Lei n. 13.140/2015 ${ }^{12}$, que cuida da mediação, se apresentam como importantes instrumentos legais.

\section{Alternative Dispute Resolution (ADR)}

O termo ADR, de Alternative Dispute Resolution, é normalmente usado em alguns países como os Estados Unidos da América (EUA) para designar uma variedade

\footnotetext{
${ }^{8}$ TAVARES, João Paulo Lordelo Guimarães. Acesso à justiça e hipossuficiência organizacional: fundamentos e amplitude da legitimação da Defensoria Pública na tutela dos direitos metaindividuais. 2013. 156f. Dissertação (Mestrado em Direito Público) Universidade Federal da Bahia, UFBA, Salvador, 2013. Disponível em: <https://repositorio.ufba.br/ri/bitstream/ri/11396/1/Disserta\%C3\%A7\%C3\%A3o\%20-\%20 Jo\%C3\%A3o\%20Paulo \%20Lordelo\%20Guimar\%C3\%A3es\%20Tavares.pdf>.

9BRASIL. Emenda Constitucional n. 80, de 04 de junho de 2014. Altera o Capítulo IV - Das Funções Essenciais à Justiça, do Título IV - Da Organização dos Poderes, e acrescenta artigo ao Ato das Disposições Constitucionais Transitórias da Constituição Federal. Disponível em <http://www.planalto.gov.br/ccivil_03/ Constituicao/Emendas/Emc/emc80.htm> Acesso em: 10 set. 2016.

${ }^{10}$ BRASIL. Lei n. 7.347, de 24 de julho de 1985. Disciplina a ação civil pública de responsabilidade por danos causados ao meio-ambiente, ao consumidor, a bens e direitos de valor artístico, estético, histórico, turístico e paisagístico (VETADO) e dá outras providências. Disponível em: <http://www.planalto.gov.br/CCivil_03/ leis/L7347Compilada.htm>. Acesso em: 02 fev. 2018.

${ }^{11}$ As partes interessadas podem submeter a solução de seus litígios ao juízo arbitral mediante convenção de arbitragem, assim entendida a cláusula compromissória e o compromisso arbitral. BRASIL. Lei n. 9.307, de 23 de setembro de 1996. Dispõe sobre a arbitragem. Disponível em: <http://www.planalto.gov.br/ ccivil_03/leis/L9307.htm>. Acesso em: 05 abr. 2017.

${ }^{12}$ Considera-se mediação a atividade técnica exercida por terceiro imparcial sem poder decisório, que, escolhido ou aceito pelas partes, as auxilia e estimula a identificar ou desenvolver soluções consensuais para a controvérsia. BRASIL. Lei n. 13.140, de 26 de junho de 2015. Dispõe sobre a mediação entre particulares como meio de solução de controvérsias e sobre a autocomposição de conflitos no âmbito da administração pública; altera a Lei no 9.469, de 10 de julho de 1997, e o Decreto no 70.235, de 6 de março de 1972; e revoga o § 20 do art. 60 da Lei no 9.469, de 10 de julho de 1997. Disponível em: <http:// www.planalto.gov.br/ccivil_03/_ato2015-2018/2015/Lei/L13140.htm>. Acesso em: 05 abr. 2017.
} 
de mecanismos de resolução de conflitos. Naquele país, a utilização de métodos de resolução de conflitos fora dos tribunais não é novidade. Todavia, o que tem se mostrado como novidade é a extensa utilização da ADR institucionalizada e promovida por meios legais e judiciais. A ADR ingressou como um movimento nos EUA na década de 1970 como uma forma de resolver as disputas sociais envolvendo direitos civis e uma alternativa ao sistema legal superlotado. Em 1990, muitos tribunais dos EUA institucionalizaram algum tipo de ADR com o objetivo de diminuir custo e tempo dos processos legais, o que resultou também em um grande aumento no número de escritórios de advocacia que passaram a oferecer serviços ligados a $\mathrm{ADR}^{13}$.

A ADR geralmente utiliza diferentes técnicas buscando uma via alternativa à utilização dos meios estatais/judiciais. No caso dos EUA, os mecanismos utilizados podem ser distinguidos entre formas vinculativas, ou seja, as partes envolvidas na ADR transferem a um terceiro de sua confiança a decisão sobre o caso, sendo que a decisão deste terceiro vincula as partes a seu cumprimento; e formas não vinculativas, ou seja, as partes chegam a um desfecho que pode ou não ser aceito pelas partes como acordo. A ADR tem se desenvolvido em diferentes países além do EUA, como Argentina, Bangladesh, Bolívia, Colômbia, Equador, Filipinas, África do Sul, Sri Lanka, Ucrânia e Uruguai. Segundo Sander e Goldberg' ${ }^{14}$, A ADR possibilita o atendimento de uma ampla variedade de objetivos sociais, comerciais, legais e políticos, como é apresentado no comparativo entre as formas de ADR (mediação e arbitragem) e o procedimento judicial na Tabela 2.

Tabela 2. Comparação entre o alcance de objetivos dos envolvidos com a utilização de mecanismos de ADR e de procedimento judicial.

\begin{tabular}{lccc}
\hline \multirow{2}{*}{ Objetivos dos envolvidos } & \multicolumn{2}{c}{ Mecanismo ADR } & Procedimento \\
\cline { 2 - 3 } & Mediação & Arbitragem & 0 \\
\hline Minimizar os custos & 3 & 1 & 0 \\
Resolver rapidamente & 3 & 1 & 0 \\
Manter a privacidade & 3 & 3 & 0 \\
Manter relações & 3 & 1 & 3 \\
Obter opinião neutra & 0 & 3 & 0 \\
\hline
\end{tabular}

Legenda: 3 - altamente possível o alcance do objetivo; 2 - possível o alcance do objetivo; 1 - improvável o alcance do objetivo; 0 - altamente improvável o alcance do objetivo.

Fonte: Adaptado pelo autor com dados de Sander e Goldberg ${ }^{15}$.

${ }^{13}$ BROWN, Scott; CERVENAK, Christine; FAIRMAN, David. Conflict Management Group (CMG). Alternative dispute resolution practitioners guide. Disponível em <https://www.usaid.gov/sites/default/files/ documents/1868/200sbe.pdf>. Acesso em 20 set. 2016.

${ }^{14}$ SANDER, F. E. A.; GOLDBERG, S. B. Fitting the Forum to the Fuss: a user-friendly guide to selecting an ADR Procedure. Negotiation Journal. 1994. Disponível em <http://onlinelibrary.wiley.com/ doi/10.1111/j.1571-9979.1994.tb00005.x/abstract> Acesso em 05 abr. 2017.

${ }^{15}$ Id. Ibid., p. 51. 
Outrossim, para os autores, a mediação e a arbitragem apresentam vantagens em relação ao procedimento judicial. Esses benefícios não se limitam apenas à questão da rapidez na solução do conflito, vez que a morosidade do Judiciário costuma ser um dos principais problemas ${ }^{16}$ apresentados, mas incluem ainda vantagens na redução dos custos e principalmente na manutenção das relações entre as partes conflitantes.

Essa busca por meios não estatais/judiciais para solução de controvérsias no âmbito da União Europeia tem importante norma na Diretiva 2008/52/CE do Parlamento Europeu e do Conselho, que trata da mediação em matéria civil e comer$\operatorname{cial}^{17}$. A norma citada no Item 6 de seus considerandos explica que a "mediação pode proporcionar uma solução extrajudicial rápida e pouco onerosa para litígios em matéria civil e comercial através de procedimentos adaptados às necessidades das partes", expondo assim os aspectos acerca da eficácia e do baixo custo da mediação. Ainda a mesma norma traz alusão à cultura da paz, que pode ser disseminada por meio da adoção da mediação, ao expressar que é "mais provável que os acordos obtidos por via de mediação sejam cumpridos voluntariamente e preservem uma relação amigável e estável entre as partes”.

Os apontamentos anteriores corroboram a noção de que a solução de controvérsias fora do meio judicial, embora não seja um fenômeno recente, passa por um processo de regulação e institucionalização em âmbito mundial. Nesse sentido, Santos ${ }^{18}$ entende que "o florescimento internacional da arbitragem e dos mecanismos conhecidos em geral por Alternative Dispute Resolution (ADR) são a manifestação mais concludente das transformações em curso nos processos convencionais de resolução de conflitos".

Dentre os diferentes temas e assuntos que podem ser objeto de ADR, está o acesso à saúde ou as disputas envolvendo questões de saúde. Para $\operatorname{Darr}^{19}$, a utilização da ADR na área de saúde traz vantagens como a privacidade dos procedimentos, $\mathrm{o}$ baixo custo econômico, a rapidez de resultados e, ainda, a possiblidade de se manterem relações abaladas pela discussão do direito em disputa.

Na Espanha, estudos têm sido realizados com o objetivo de alargar a utilização dos sistemas extrajudiciales de resolución de conflicto, a fim de aplicar a mediação de não só na prática, mas também na legislação. Armadans et al. ${ }^{20}$, tratando da questão da

\footnotetext{
${ }^{16}$ SANTOS, Boaventura de Sousa. Para uma revolução democrática da justiça. São Paulo: Cortez, 2007.

${ }^{17}$ DIRECTIVA 2008/52/CE DO PARLAMENTO EUROPEU E DO CONSELHO, 21 de maio de 2008, relativa a certos aspectos da mediação em matéria civil e comercial. Disponível em <http://eur-lex.europa.eu/legalcontent/PT/ALL/?uri=CELEX:32008L0052> Acesso em: 28 set. 2016.

${ }^{18}$ SANTOS, Boaventura de Sousa. Pela mão de Alice: o social e o político na Pós-Modernidade, cit., p. 157.

${ }^{19}$ DARR, Kurt. Alternative dispute resolution in health services: now more than ever. Hospital Topcis, Washington, DC, v. 72, n. 4, 1994. Disponível em <http://www.tandfonline.com/doi/abs/10.1080/00185 868.1994.9948494>. https://doi.org/10.1080/00185868.1994.9948494.

${ }^{20}$ ARMADANS, Immaculada et al. La mediación en el ámbito de la salud. Medicina Clinica, Barcelona, v. 133, n. 5, p. 187-192, 2009.
} 
mediação no âmbito da saúde na Espanha, sugerem a utilização nas áreas de mediação sanitária, nas demandas por negligência médica e na mediação intercultural em saúde.

No Brasil, segundo Grinover ${ }^{21}$, os marcos regulatórios que disciplinam os métodos consensuais são três: (a) a Resolução n. 125/2010²2, do Conselho Nacional de Justiça (CNJ); (b) a Lei n. 13.105/2015²3 (Código de Processo Civil); e (c) a Lei n. $13.140 / 2015^{24}$, que trata da mediação. Também por aqui se tem usado a mediação como alternativa para a solução de conflitos na área de saúde.

\section{Mediação como alternativa para a solução de conflitos na área de saúde}

O fenômeno conhecido como judicialização da saúde - entendido como “o envolvimento do Poder Judiciário na esfera política" 25 - não é novo; é estudado desde a década de 1990, a partir dos primeiros processos judiciais envolvendo o fornecimento de medicamentos para o tratamento de HIV/Aids ${ }^{26}$.

Por sua complexidade e abrangência, envolvendo diversas áreas do conhecimento jurídico, o tema é discutido sob diferentes enfoques, como (a) a possibilidade da justiciabilidade de direitos sociais ${ }^{27},{ }^{28}$; (b) de a judicialização promover o antagonismo do direito social contra os pobres ${ }^{29},{ }^{30} ;$ (c) o interesse da indústria farmacêutica

${ }^{21}$ GRINOVER, Ada Pellegrini. Os métodos consensuais de solução de conflitos no novo Código de Processo Civil. Prodireito. Direito Processual Civil. Ciclo 1. Volume 1. Disponível em <http://www.migalhas.com.br/ arquivos/2016/1/art20160105-01.pdf> Acesso em: 30 set. 2016.

${ }^{22}$ BRASIL. Conselho Nacional de Justiça. Resolução n. 125, de 29 de novembro de 2010. Dispõe sobre a Política Judiciária Nacional de tratamento adequado dos conflitos de interesses no âmbito do Poder Judiciário e dá outras providências. Disponível em: <http://www.cnj.jus.br/busca-atos-adm?documento=2579>. Acesso em: 02 fev. 2018.

${ }^{23}$ BRASIL. Lei n. 13.105, de 16 de março de 2015. Código de Processo Civil. Disponível em: <http://www. planalto.gov.br/ccivil_03/_ato2015-2018/2015/lei/I13105.htm>. Acesso em: 02 fev. 2018.

${ }^{24}$ BRASIL. Lei n. 13.140, de 25 de junho de 2015. Dispõe sobre a mediação entre particulares como meio de solução de controvérsias e sobre a autocomposição de conflitos no âmbito da administração pública; altera a Lei $n^{\circ}$ 9.469, de 10 de julho de 1997, e o Decreto $n^{\circ} 70.235$, de 6 de março de 1972; e revoga o $\S 2^{\circ}$ do art. $6^{\circ}$ da Lei $n^{\circ} 9.469$, de 10 de julho de 1997. Disponível em: <http://www.planalto.gov.br/ ccivil_03/_ato2015-2018/2015/lei/L13140.htm>. Acesso em: 02 fev. 2018.

${ }^{25}$ BORGES, Danielle da Costa Leite; UGÁ, Maria Alicia Dominguez. As ações individuais para o fornecimento de medicamentos no âmbito do SUS: características dos conflitos e limites para a atuação judicial. Revista de Direito Sanitário, São Paulo v. 10, n. 1 p. 13-38, mar./jul. 2009. Disponível em: <http://www.revistas. usp.br/rdisan/article/view/13144>. http://dx.doi.org/10.11606/issn.2316-9044.v10i1p13-38.

${ }^{26}$ OLIVEIRA, Maria dos Remédios Mendes et al. Mediação: um meio de desjudicializar a saúde. Tempus, actas de saúde colet, Brasília, v. 10, n. 1, p. 169-177, mar. 2016. Disponível em: <https://www.researchgate.net/ publication/303439586_Mediacao_um_meio_de_desjudicializar_a_saude>. Acesso em: 05 abr. 2017. 10.18569/tempus.v10i1.1860.

${ }^{27}$ DINIZ, Maria Gabriela Araújo. Direito social em favor dos pobres: perspectivas da adoção de meios alternativos de solução de controvérsias nos conflitos de direito à saúde. Caderno lberoAmericano de Direito Sanitário, Brasília, v. 2, n. 2, p. 472-485, jul./dez. 2003. Disponível em <http://www.cadernos. prodisa.fiocruz.br/index.php/cadernos/article/view/99>. http://dx.doi.org/10.17566/ciads.v2i2.

${ }^{28}$ PIOVESAN, Flávia. Justiciabilidade dos direitos sociais e econômicos: desafios e perspectivas. Revista da Defensoria Pública, ano 1, n. 1, p. 128-146, jul./dez. 2008.

${ }^{29} \mathrm{CHIEFFI}$, Ana Luiza; BARATA, Rita Barradas. Judicialização da política pública de assistência farmacêutica e equidade. Cad. Saúde Pública, Rio de Janeiro, v. 25, n. 8, p. 1839-1849, ago. 2009. Disponível em <http:// www.scielo.br/pdf/csp/v25n8/20.pdf>. http://dx.doi.org/10.1590/S0102-311X2009000800020.

${ }^{30} \mathrm{DINIZ}$, Maria Gabriela Araújo. op. cit. 
na distribuição de medicamentos de alto custo ${ }^{31}$; (d) as falhas na Sistema Único de Saúde (SUS) ${ }^{32}$; entre outros.

Nesse contexto de judicialização crescente de direitos sociais, algumas iniciativas têm sido buscadas e implementadas com a finalidade de diminuir o número de demandas envolvendo o tema, usando em especial alguma forma institucionalizada de mediação. Esta pesquisa encontrou três iniciativas institucionalizadas de aplicação de mediação na área de saúde: (a) mediação sanitária promovida pelo Ministério Público de Minas Gerais; (b) no Distrito Federal, a Câmara Permanente Distrital de Mediação em Saúde (Camedis); e (c) Comitê Interinstitucional de Resolução Administrativa de Demandas da Saúde (Cirads), no Rio Grande do Norte.

No estado de Minas Gerais, o Ministério Público, por meio do Centro de Apoio Operacional das Promotorias de Justiça e Defesa da Saúde (CAO/Saúde), tem promovido ações de mediação sanitária com o fito de realizar encontros entre o Poder Judiciário, o ministério público, a defensoria pública, gestores e conselheiros municipais, entidades do terceiro setor e pessoas da comunidade a fim de discutir questões relacionadas à saúde individual ou pública. Segundo $A s s i s^{33}$, a mediação sanitária é uma proposta institucional criada pelo Ministério Público de Minas Gerais “que visa discutir os desafios (problemas-causas) coletivos de saúde, no âmbito micro ou macrorregional, a partir do seu ativismo em uma agenda que possa envolver todos os atores do Sistema, jurídicos ou não”. A idealização da mediação sanitária parte da percepção de duas situações político-institucionais: (a) o impacto negativo da judicialização da saúde no orçamento e no planejamento coletivo da saúde; e (b) a "necessidade da (re)organização das ações e serviços de saúde, no âmbito regional, de forma solidária e não solitária, com participação democrática, visando a elaboração desse mesmo planejamento de saúde numa perspectiva integrada e regional"34. A mediação sanitária pode ocorrer tanto em assuntos de saúde pública como em assuntos de natureza suplementar em que estejam envolvidos interesses tutelados pelo Ministério Público.

No Distrito Federal, a Camedis, instituída por ação conjunta da Secretaria de Estado de Saúde e da Defensoria Pública do Distrito Federal, tem como missão "buscar a solução às demandas por serviços e produtos de saúde no intuito de evitar ações judiciais e propor soluções para aquelas em trâmite”35. Trata-se de um espaço

\footnotetext{
${ }^{31}$ OLIVEIRA, Maria dos Remédios Mendes et al. Judicialização da saúde: para onde caminham as produções científicas? Saúde Debate, Rio de Janeiro, v. 39, n. 105, p. 525-535, abr./jun. 2015. Disponível em: <http://www.scielo.br/pdf/sdeb/v39n105/0103-1104-sdeb-39-105-00525.pdf>. Acesso em: 05 abr. 2017. http://dx.doi.org/10.1590/0103-1104201510500020.

${ }^{32}$ Id. Ibid.

${ }^{33}$ ASSIS, Gilmar de. Medição sanitária. Cad. IberAmer. Direito. Sanit., Brasília, v. 2, n. 2, jul./dez. 2013. Anais dos III Congresso Iberoamericano de Direito Sanitário / II Congresso Brasileiro de Direito Sanitário. Disponível em: <http:// www.cadernos.prodisa.fiocruz.br/index.php/cadernos/article/download/98/140> Acesso em: 04 set. 2016. ${ }^{34}$ Id. Ibid.

${ }^{35}$ PAIM, Patrícia; MARQUETO, Alessandra; LOPES, Ivaneide de Oliveira. Câmara Permanente Distrital de Mediação em Saúde: experiência do Distrito Federal. 1. ed. Brasília: Conselho Nacional de Secretários de Saúde - CONASS, 2015 Disponível em <www.conass.org.br>. Acesso em: 04 out. 2016.
} 
de mediação em que a Defensoria Pública do Distrito Federal atua como mediadora nas questões envolvendo algum conflito entre cidadãos e a secretaria de saúde. Ainda segundo a Portaria Conjunta n. 01/2013 $3^{36}$, a Camedis é "responsável por mediação relativa às demandas por serviços ou produtos de saúde oferecidos pelo Sistema Único de Saúde (SUS) no Distrito Federal". A Camedis conta com um cronograma de reuniões periódicas, sendo que, além da Defensoria Pública e da Secretária de Estado de Saúde do Distrito Federal, ainda poderão ser chamados para participar órgãos ou entidades da administração pública, ministério público, entes privados nacionais e internacionais e instituições de ensino.

No Cirads, por meio de ação conjunta, a Procuradoria da União no Rio Grande do Norte, a Defensoria Pública da União, procuradores estaduais e municipais e secretarias estaduais e municipais de saúde visam a solucionar, administrativamente, demandas envolvendo o cidadão e o SUS ${ }^{37}$. A mesma iniciativa tem sido estendida a outros estados, como Pará e Bahia. O Cirads busca a solução administrativa dos conflitos na área de saúde, por meio da análise de casos concretos em que o cidadão não conseguiu resolver sua pendência diretamente com $o$ SUS. Assim, o Cirads busca dar suporte administrativo a questões que podem ser resolvidas extrajudicialmente, evitando a judicialização e oferecendo alternativas àqueles conflitos já judicializados.

Para Delduque e Castro ${ }^{38}$, a adesão a meios alternativos de solução de conflitos, especialmente a mediação, busca realizar "uma lenta transformação da sociedade brasileira, no sentido de criar a cultura do consenso e da cooperação na composição das disputas, aceitando-se um polissêmico conceito de justiça”. Ainda para os mesmos autores, a mediação sanitária se apresenta como uma possibilidade de discutir as elações na área da saúde, diante da natureza do tema envolvido - que transcende a ótica bilateral da relação entre médico e paciente, envolvendo vários outros indivíduos, instituições e interesses.

Entretanto, essa transformação que se espera da mediação como solução pacífica de conflitos e a consequente diminuição da judicialização da saúde não devem ser realizadas de forma generalizada, e muito menos desacompanhadas de criteriosa fiscalização por instituições de caráter imparcial e comprometidas com o acesso e a realização da justiça. Se é certo que a judicialização da saúde traz consequências deletérias para o Estado e para a sociedade, também não se pode descurar que os direitos

\footnotetext{
${ }^{36}$ DISTRITO FEDERAL. Portaria Conjunta n. 01, de 26 de fevereiro de 2013. Institui a Câmara Permanente Distrital de Mediação em Saúde (CAMEDIS). Disponível em <http://www.tjdft.jus.br/institucional/comite-executivo-distritalda-saude/camedis/portaria-conjunta-no-01-de-26-de-fevereiro-de-2013/view>. Acesso em: 05 abr. 2017.

${ }^{37}$ ADVOCACIA GERAL DA UNIÃO. O que é o CIRADS? Disponível em <http://www.agu.gov.br/page/content/ detail/id_conteudo/97046>. Acesso em: 04 out. 2016.

${ }^{38}$ DELDUQUE, Maria Célia; CASTRO, Eduardo Vazquez. A mediação sanitária como alternativa viável à judicialização das políticas de saúde no Brasil. Saúde Debate, Rio de Janeiro, v. 39, n. 105, p. 506-513, abr./ jun. 2015. Disponível em <http://www.scielo.br/pdf/sdeb/v39n105/0103-1104-sdeb-39-105-00506. pdf>. http://dx.doi.org/10.1590/0103-110420151050002017.
} 
sociais precisam ser implementados e respeitados. Não obstante a via escolhida para resolver a questão conflituosa, é sempre o direito da pessoa que deve ser privilegiado, haja vista os valores constitucionais envolvidos. Isso porque, como ressalta Santos $^{39}$, "a diminuição relativa do contencioso civil detectada em vários países tem sido considerada disfuncional, ou seja, como negativa em relação ao processo de democratização da justiça"; ainda segundo o autor, "se é certo que as classes de menores recursos tendem a não utilizar a justiça pelas razões que expusemos, a verdade é que as classes de maiores recursos tendem igualmente a resolver os seus litígios fora do campo judiciário" (pois muitas vezes a utilização dos meios judiciais poderia dar uma visibilidade incômoda aos interesses das classes de maiores recursos).

\section{Considerações finais}

Os movimentos pretéritos e atuais que buscam a diminuição da marginalização e a ampliação do acesso à justiça têm atuado dentro e fora do Judiciário com o fito de alcançar o desiderato que propõem. Nesse sentido, os defensores dos mecanismos de mediação têm apresentado uma evolução consistente em argumentos e condições para sua implementação.

A mediação sanitária situada nesta seara apresenta-se como uma importante ferramenta, colocada à disposição das instituições dentro e fora do Poder Judiciário com a finalidade de possibilitar uma cultura baseada no entendimento entre as partes, com custos e prazos menores, além da desejada manutenção das relações antes conflituosas. Relevantes e bem intencionadas iniciativas têm sido apresentadas e implementadas em diferentes regiões do país, com significativos ganhos para as partes envolvidas, podendo-se destacar a mediação sanitária pelo CAO/Saúde em Minas Gerais, pela Camedis no Distrito Federal e pelo Cirads no Rio Grande do Norte.

Todavia, não há que se descurar do necessário entendimento de que a mediação não é uma panaceia para todos os males, que, mesmo na seara da autocomposição, outros mecanismos são possíveis e que diferentes situações podem necessitar de diferentes técnicas de resolução de controvérsias.

Além disso, deve-se admitir também que a mediação deve ser atrelada a participação de instituições neutras e comprometidas com o acesso e a realização da justiça aplicada ao caso concreto. Não é despiciendo lembrar que a mediação, para além dos contornos sociais que a ela têm sido dispensados, também é uma técnica muito utilizada por conglomerados econômicos ansiosos por proteger segredos financeiros e industriais. Assim, há que se ponderar a utilização da mediação como instrumento de promoção e acesso à justiça, não se descuidando das condições e possibilidades de sua realização para que não se torne em instrumento de obtenção de vantagem por certos interesses privilegiados.

\footnotetext{
${ }^{39}$ SANTOS, Boaventura de Sousa. Pela mão de Alice: o social e o político na Pós-Modernidade, cit.
} 


\section{Referências}

ADVOCACIA GERAL DA UNIÃO. O que é o CIRADS? Disponível em <http://www.agu. gov.br/page/content/detail/id_conteudo/97046>. Acesso em: 04 out. 2016.

ARMADANS, Immaculada et al. La mediación en el ámbito de la salud. Medicina Clinica, Barcelona, v. 133, n. 5, p. 187-192, 2009.

ASENSI, Felipe Dutra; PINHEIRO, Roseni (Coords.). Judicialização da saúde no Brasil: dados e experiência. Brasília: Conselho Nacional de Justiça, 2015.

ASSIS, Gilmar de. Medição sanitária. Cad. IberAmer. Direito. Sanit., Brasília, v. 2, n. 2, jul./dez. 2013. Anais dos III Congresso Iberoamericano de Direito Sanitário / II Congresso Brasileiro de Direito Sanitário. Disponível em: <http://www.cadernos.prodisa.fiocruz.br/index.php/ cadernos/article/download/98/140> Acesso em: 04 set. 2016.

BORGES, Danielle da Costa Leite; UGÁ, Maria Alicia Dominguez. As ações individuais para o fornecimento de medicamentos no âmbito do SUS: características dos conflitos e limites para a atuação judicial. Revista de Direito Sanitário, São Paulo v. 10, n. 1 p. 13-38, mar./jul. 2009. Disponível em: <http://www.revistas.usp.br/rdisan/article/view/13144>. http://dx.doi. org/10.11606/issn.2316-9044.v10i1p13-38.

BROWN, Scott; CERVENAK, Christine; FAIRMAN, David. Conflict Management Group (CMG). Alternative dispute resolution practitioners guide. Disponível em $<\mathrm{https}$ ://www.usaid. gov/sites/default/files/documents/1868/200sbe.pdf>. Acesso em 20 set. 2016.

CAPPELLETTI, Mauro; GARTH, Bryant. Acesso à justiça. Reimpr. Tradução Ellen Gracie Northfleet. Porto Alegre: Fabris, 2015.

CHIEFFI, Ana Luiza; BARATA, Rita Barradas. Judicialização da política pública de assistência farmacêutica e equidade. Cad. Saúde Pública, Rio de Janeiro, v. 25, n. 8, p. 1839-1849, ago. 2009. Disponível em <http://www.scielo.br/pdf/csp/v25n8/20.pdf >. http://dx.doi.org/10.1590/ S0102-311X2009000800020.

DARR, Kurt. Alternative dispute resolution in health services: now more than ever. Hospital Topcis, Washington, DC, v. 72, n. 4, 1994. Disponível em <http://www.tandfonline.com/doi/ abs/10.1080/00185868.1994.9948494>. https://doi.org/10.1080/00185868.1994.9948494.

DELDUQUE, Maria Célia; CASTRO, Eduardo Vazquez. A mediação sanitária como alternativa viável à judicialização das políticas de saúde no Brasil. Saúde Debate, Rio de Janeiro, v. 39, n. 105, p. 506-513, abr./jun. 2015. Disponível em <http://www.scielo.br/pdf/sdeb/v39n105/01031104-sdeb-39-105-00506.pdf>. http://dx.doi.org/10.1590/0103-110420151050002017.

DINIZ, Maria Gabriela Araújo. Direito social em favor dos pobres: perspectivas da adoção de meios alternativos de solução de controvérsias nos conflitos de direito à saúde. Caderno IberoAmericano de Direito Sanitário, Brasília, v. 2, n. 2, p. 472-485, jul./dez. 2003. Disponível em <http://www.cadernos.prodisa.fiocruz.br/index.php/cadernos/article/view/99>. http://dx.doi.org/10.17566/ciads.v2i2.99. 
GRINOVER, Ada Pellegrini. Os métodos consensuais de solução de conflitos no novo Código de Processo Civil. Prodireito. Direito Processual Civil. Ciclo 1. Volume 1. Disponível em <http://www.migalhas.com.br/arquivos/2016/1/art20160105-01.pdf> Acesso em: 30 set. 2016.

IBGE - INSTITUTO BRASILEIRO DE GEOGRAFIA E ESTATÍSTICA. Pesquisa Nacional por Amostra de Domicílios - PNAD. Características da vitimização e do acesso à justiça no Brasil. 2009. Disponível em <http://biblioteca.ibge.gov.br/visualizacao/livros/liv47311.pdf> Acesso em: 05 abr. 2017.

IPEA - INSTITUTO DE PESQUISA ECONÔMICA APLICADA. Sistema de Indicadores de percepção Social. Justiça, 31 maio 2011. Disponível em <http://www.ipea.gov.br/portal/ images/stories/PDFs/SIPS/110531_sips_justica.pdf> Acesso em: 05 abr. 2017.

OLIVEIRA, Maria dos Remédios Mendes et al. Judicialização da saúde: para onde caminham as produções científicas? Saúde Debate, Rio de Janeiro, v. 39, n. 105, p. 525-535, abr./jun. 2015. Disponível em: <http://www.scielo.br/pdf/sdeb/v39n105/01031104-sdeb-39-105-00525.pdf>. Acesso em: 05 abr. 2017. http://dx.doi.org/10.1590/0103110420151050002019 .

OLIVEIRA, Maria dos Remédios Mendes et al. Mediação: um meio de desjudicializar a saúde. Tempus, actas de saúde colet, Brasília, v. 10, n. 1, p. 169-177, mar. 2016. Disponível em: <https:// www.researchgate.net/publication/303439586_Mediacao_um_meio_de_desjudicializar_a_ saude> Acesso em: 05 abr. 2017. 10.18569/tempus.v10i1.1860.

PAIM, Patrícia; MARQUETO, Alessandra; LOPES, Ivaneide de Oliveira. Câmara Permanente Distrital de Mediação em Saúde: experiência do Distrito Federal. 1. ed. Brasília: Conselho Nacional de Secretários de Saúde - CONASS, 2015 Disponível em <www.conass.org.br> Acesso em: 04 out. 2016.

PIOVESAN, Flávia. Justiciabilidade dos direitos sociais e econômicos: desafios e perspectivas. Revista da Defensoria Pública, ano 1, n. 1, p. 128-146, jul./dez. 2008.

SANDER, F. E. A. GOLDBERG, S. B. Fitting the Forum to the Fuss: a user-friendly guide to selecting an ADR Procedure. Negotiation Journal. 1994. Disponível em <http://onlinelibrary. wiley.com/doi/10.1111/j.1571-9979.1994.tb00005.x/abstract> Acesso em 05 abr. 2017.

SANTOS, Boaventura de Sousa. Para uma revolução democrática da justiça. São Paulo: Cortez, 2007.

SANTOS, Boaventura de Sousa. Pela mão de Alice: o social e o político na Pós-Modernidade. 7. ed. Porto: Edições Afrontamento, 1999.

TAVARES, João Paulo Lordelo Guimarães. Acesso à justiça e hipossuficiência organizacional: fundamentos e amplitude da legitimação da Defensoria Pública na tutela dos direitos metaindividuais. 2013. 156f. Dissertação (Mestrado em Direito Público) Universidade Federal da Bahia, UFBA, Salvador, 2013. Disponível em: <https://repositorio.ufba.br/ri/bitstream/ ri/11396/1/Disserta\%C3\%A7\%C3\%A3o\%20-\%20Jo\%C3\%A3o\%20Paulo \%20Lordelo\%20 Guimar\%C3\%A3es\%20Tavares.pdf>. 
VIANNA, Luiz Werneck; BURGOS, Marcelo Baumann; SALLES, Paula Martins. Dezessete anos de judicialização da política. Tempo soc., São Paulo, v. 19, n. 2, p. 39-85, nov. 2007. Disponível em <http://www.scielo.br/scielo.php?script=sci_arttext\&pid=S010320702007000200002\&lng=pt\&nrm=iso $>$. Acesso em: 07 abr. 2017. http://dx.doi.org/10.1590/ S0103-20702007000200002.

Wesllay Carlos Ribeiro - Doutor em Direito pela Pontifícia Universidade Católica de Minas Gerais; mestre em Direito pela Universidade Estácio de Sá; graduado em Direito pela Faculdade de Direito de Varginha. Professor adjunto da Universidade Federal de Alfenas. Varginha/MG, Brasil. E-mail: wesllay.ribeiro@gmail.com. 